\title{
Atomic-Level Electronic Properties of Carbon
}

\section{Nitride Monolayers}

Dingguan Wang, ${ }^{, \neq} \neq$Zishen Wang,,, $\mathcal{S}$ Wei Liu,, Arramel, $\neq$ Jun Zhou, $\neq$ Yuan Ping Feng,,$\neq \mathcal{S}$

Kian Ping Loh,t,\& Jishan Wu, ,t and Andrew T. S. Wee ${ }^{*},, \mathcal{S}$

†Department of Chemistry, National University of Singapore, 3 Science Drive 3,

Singapore 117543, Singapore

狍epartment of Physics, National University of Singapore, 2 Science Drive 3, Singapore

117551, Singapore

\$Centre for Advanced 2D Materials and Graphene Research Centre, National University

of Singapore, 3 Science Drive 3, Singapore 117546, Singapore. 
${ }^{*}$ Correspondence and requests for materials should be addressed to Prof. J. Wu (Email: chmwuj@nus.edu.sg) or Prof. A. T. S.Wee (E-mail: phyweets@nus.edu.sg)

a

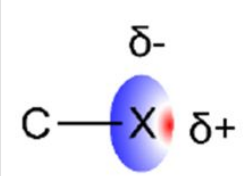

Anisotropic electron distribution

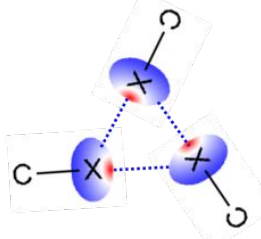

Triple halogen bond
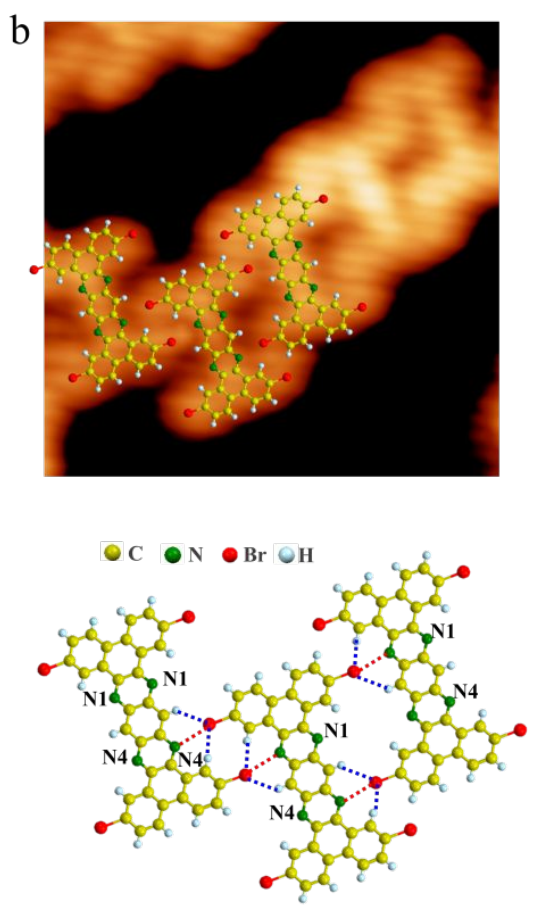

C
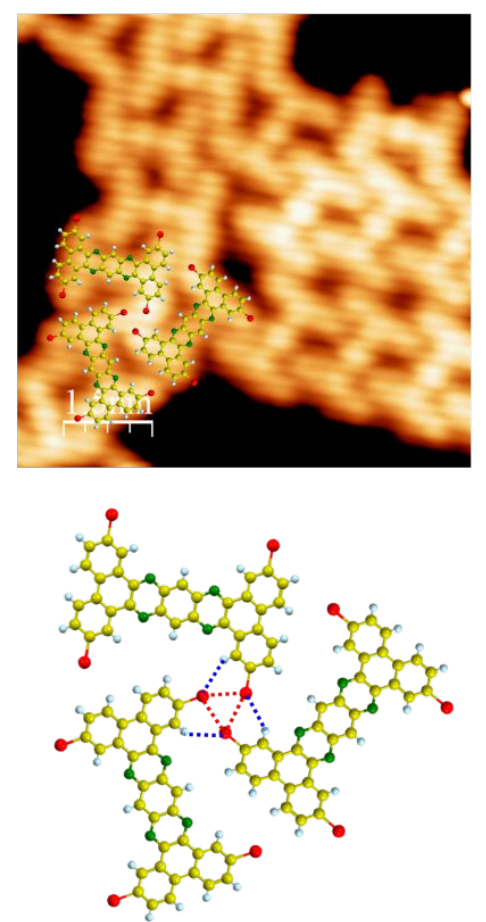

Figure S1. Self-assembly of $<1 \mathrm{ML} 4 \mathrm{~N}$-doped molecule on $\mathrm{Au}(111)$. a) Triple halogen bond scheme. Anisotropic electron distribution on $\mathrm{Br}$ atom (X) represented by an ellipse, $\delta+$ and $\delta$ denote the electron depletion and accumulation regions. The red and blue colors indicate the positive and negative electrostatic potential (Han et al., Science 2017, 358, 206-210); b) The self-assembly was driven by $\mathrm{Br}-\mathrm{N}$ interaction and $\mathrm{Br}-\mathrm{H}$ interaction, set point: $V=1.5 \mathrm{~V}$ and $I=$ 
$36 \mathrm{pA}$, size: $5.4 \mathrm{~nm} \times 5.4 \mathrm{~nm}$; c) The self-assembly was driven by triple $\mathrm{Br}-\mathrm{Br}$ interaction and $\mathrm{Br}-\mathrm{H}$ interaction. The respective ball-stick models of molecular arrangements are provided. The $\mathrm{Br}-\mathrm{N}$ and the B-H interactions are indicated by the red and blue dashed lines, respectively.
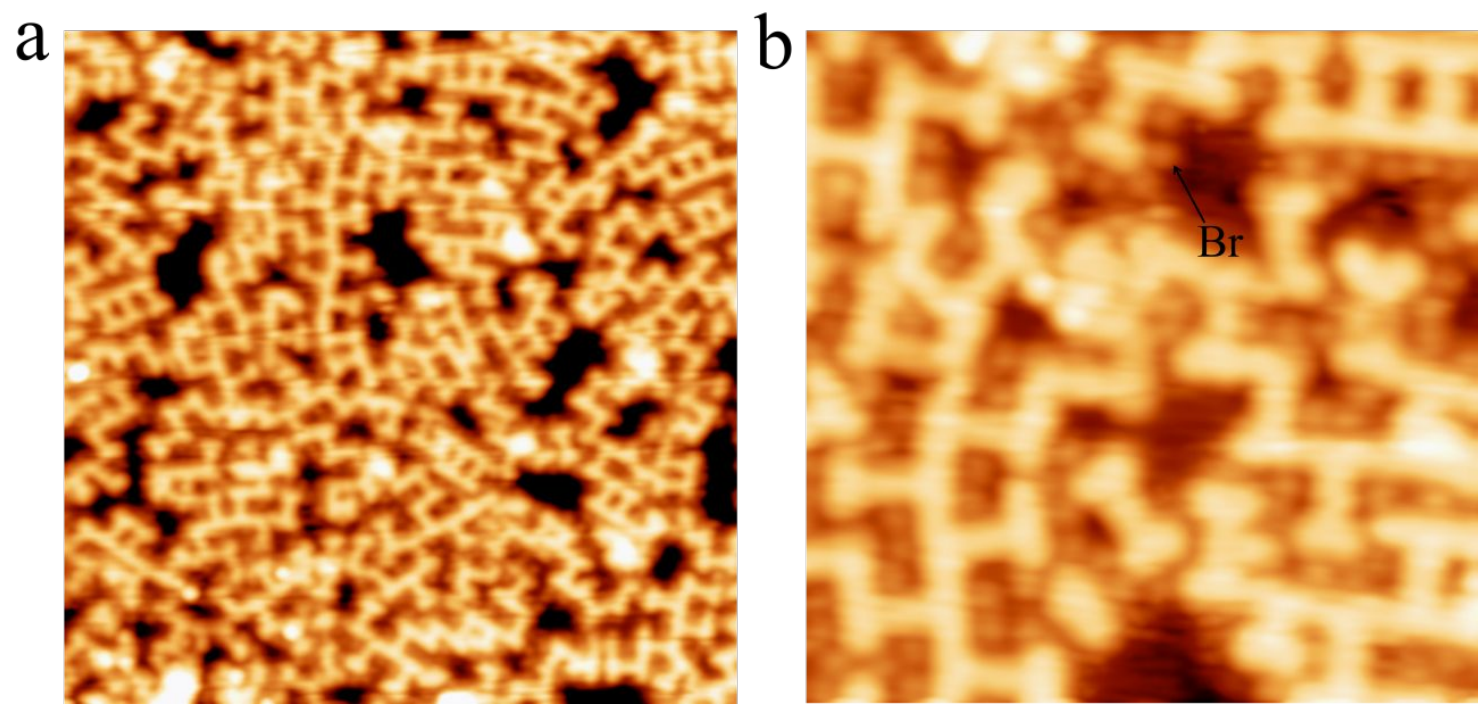

Figure S2. In-situ cleaved $\mathrm{Br}$ atom adsorbed on $\mathrm{Au}(111)$ surface. a) Large-scale and b) zoom-in STM images of a single layer of $2 \mathrm{D}$ carbon nitride after annealing at $200{ }^{\circ} \mathrm{C}$, the black arrow highlights Br bright point; a) set point: $V=0.7 \mathrm{~V}$ and $I=116 \mathrm{pA}$, size: $30 \mathrm{~nm} \times 30 \mathrm{~nm}$, b) set point: $V=0.1 \mathrm{~V}$ and $I=15 \mathrm{pA}$, size: $10 \mathrm{~nm} \times 10 \mathrm{~nm}$. 

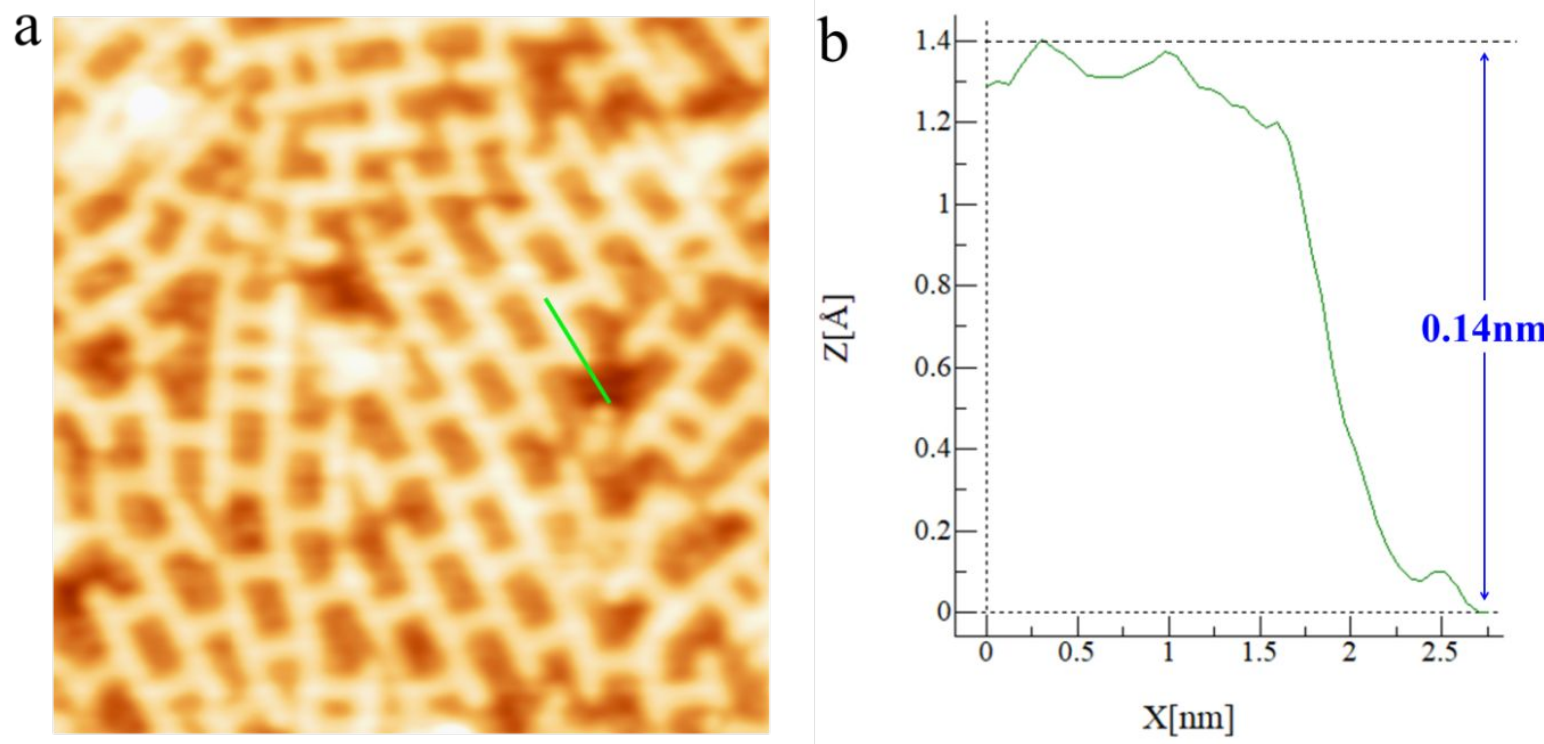

Figure S3. STM image and its corresponding height profile of a single layer of 2D 4N-doping carbon nitride. a) STM image of a single layer of 2D 4N-doping carbon nitride after annealing at $280^{\circ} \mathrm{C}$, set point: $V=0.1 \mathrm{~V}$ and $I=50 \mathrm{pA}$, size: $16 \mathrm{~nm} \times 16 \mathrm{~nm}$; b) Corresponding height profile of green cross-sections line in a, the height of $\sim 0.14 \mathrm{~nm}$ reveals a single layer of as-synthesized 2D 4N-doping carbon nitride. 

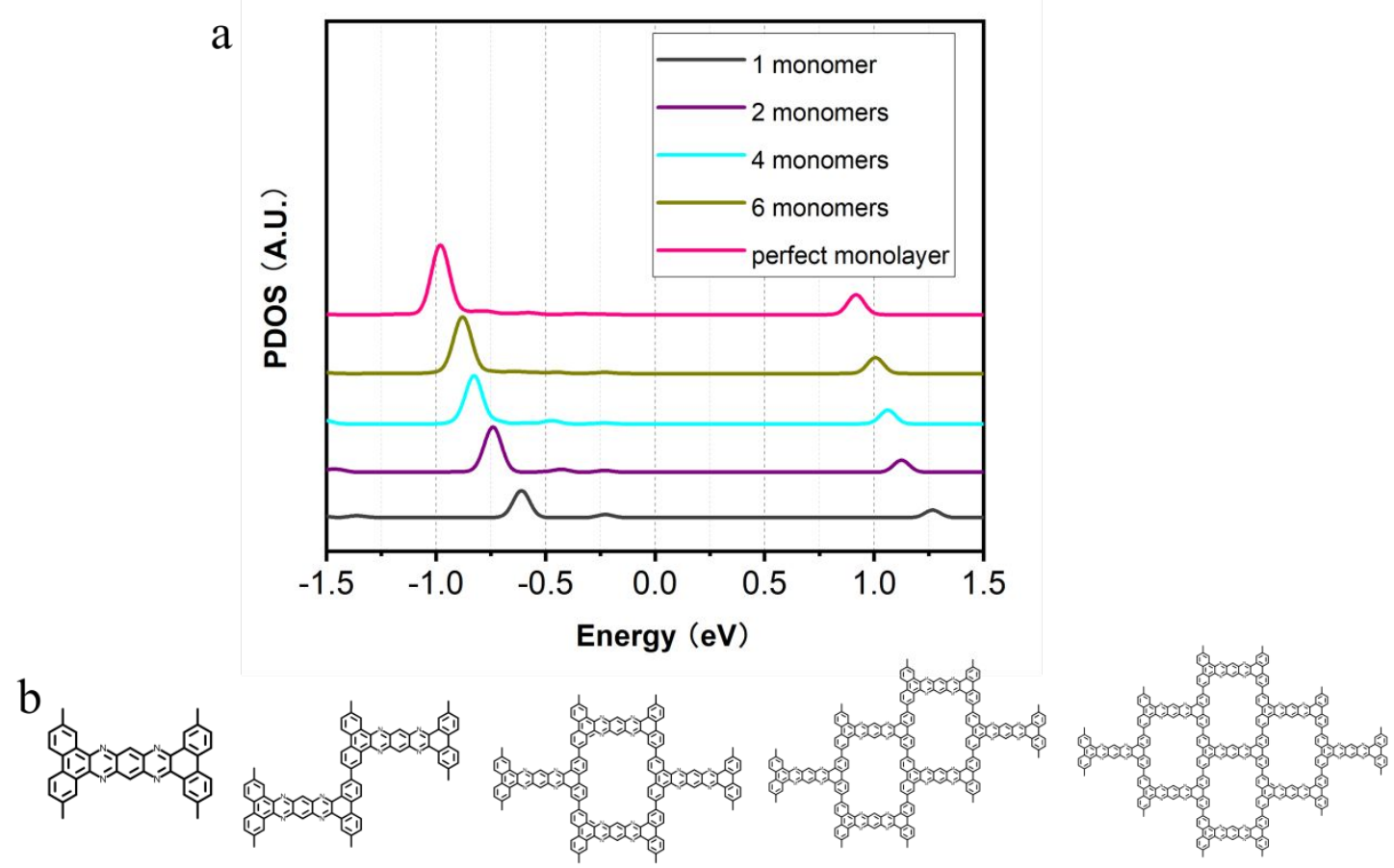

\section{1 monomer 2 monomers 4 monomers 6 monomers Perfect monolayer}

Figure S4. Theoretical electronic structure of size-dependent carbon nitride oligomers. a) Theoretical nitrogen PDOS and b) molecular structure of carbon nitride oligomers. 
$\mathrm{a}$

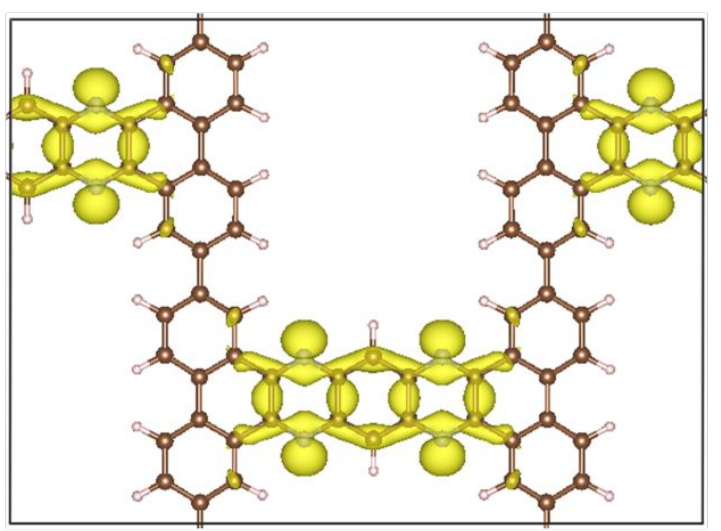

$\mathrm{b}$

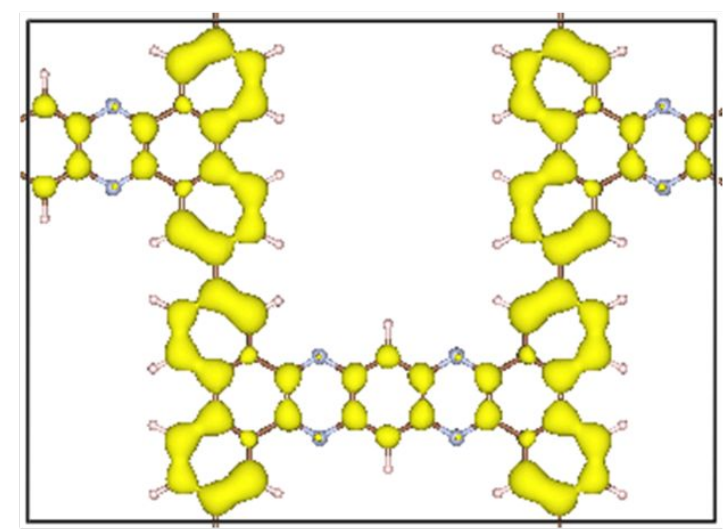

Figure S5. Partial charge density distribution for 2D 4N-doping carbon nitride state a) at the VB maximum (-0.9 eV to $-1.05 \mathrm{eV})$ and $\mathrm{b})$ at the $\mathrm{VB}-1$ maximum $(-1.11 \mathrm{eV}$ to $-1.21 \mathrm{eV})$, partial charge density isosurface plotted at $0.006 \mathrm{e}^{\mathrm{Bohr}}{ }^{3}$ and $0.0012 \mathrm{e} / \mathrm{Bohr}^{3}$ for $\mathrm{VB}$ and VB-1, respectively. 

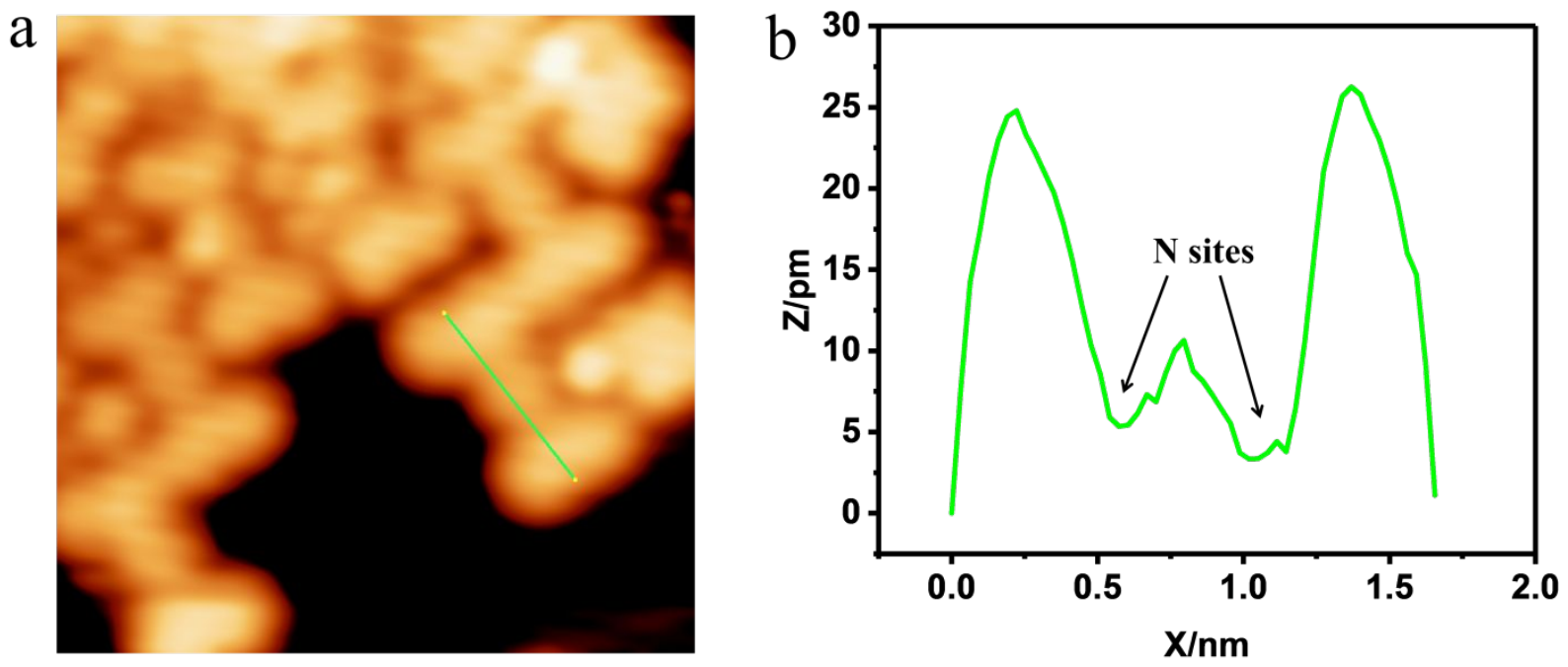

Figure S6. a) High-resolution STM image indicates the sum of the LDOS of the VB-1 and VB of 2D 4N-doping carbon nitride, set point: $V=-2.0 \mathrm{~V}$ and $I=65 \mathrm{pA}$, size: $5.0 \mathrm{~nm} \times 5.0 \mathrm{~nm}$; b) Corresponding profiles for green cross-sections line in a, nitrogen site is about 20 pm lower than carbon site, which indicates that doping nitrogen disturbs $\pi$-electron wave function in carbon frameworks. 

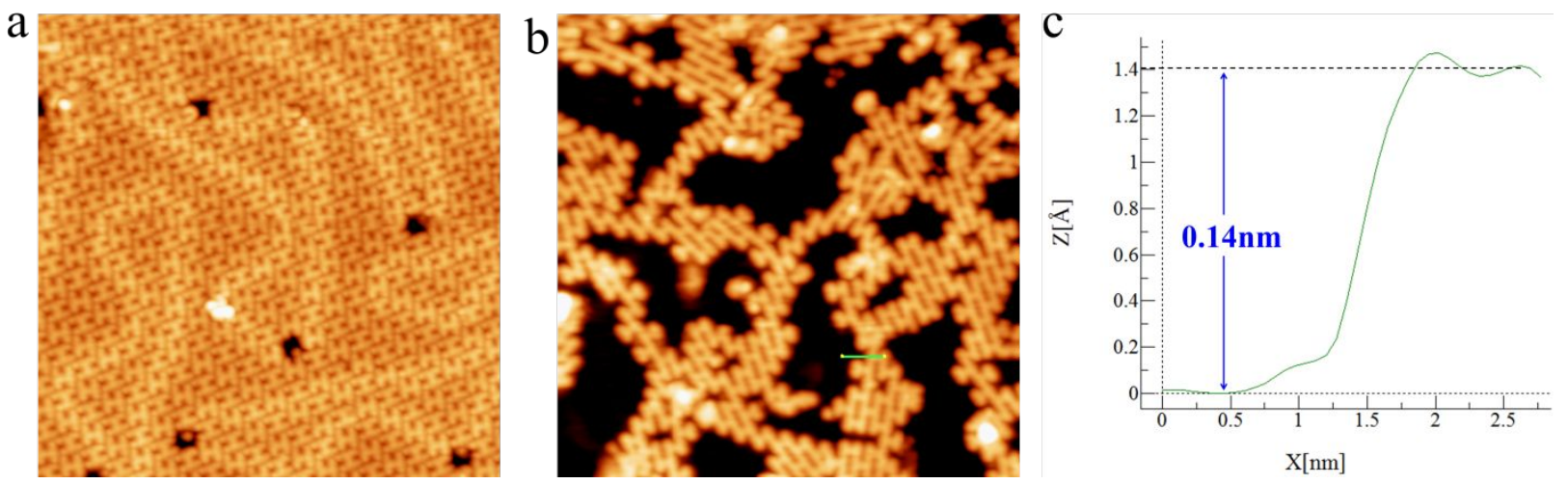

Figure S7. a) A large STM image of a self-assembly monolayer of room-temperature deposition of precursor TBTBP on $\mathrm{Au}(111)$, set point: $V=-1.0 \mathrm{~V}$ and $I=50 \mathrm{pA}$, size: $30 \mathrm{~nm} \times 30 \mathrm{~nm}$; b) A large STM image of a single layer of 2D $2 \mathrm{~N}$-doping carbon nitride after annealing at $250^{\circ} \mathrm{C}$, set point: $V=0.5 \mathrm{~V}$ and $I=54 \mathrm{pA}$. size: $30 \mathrm{~nm} \times 30 \mathrm{~nm}$; c) Corresponding height profiles for green cross-sections line in $\mathrm{b}$, a height of $\sim 0.14 \mathrm{~nm}$ indicates a single layer of $2 \mathrm{D} 2 \mathrm{~N}$-doping carbon nitride. 

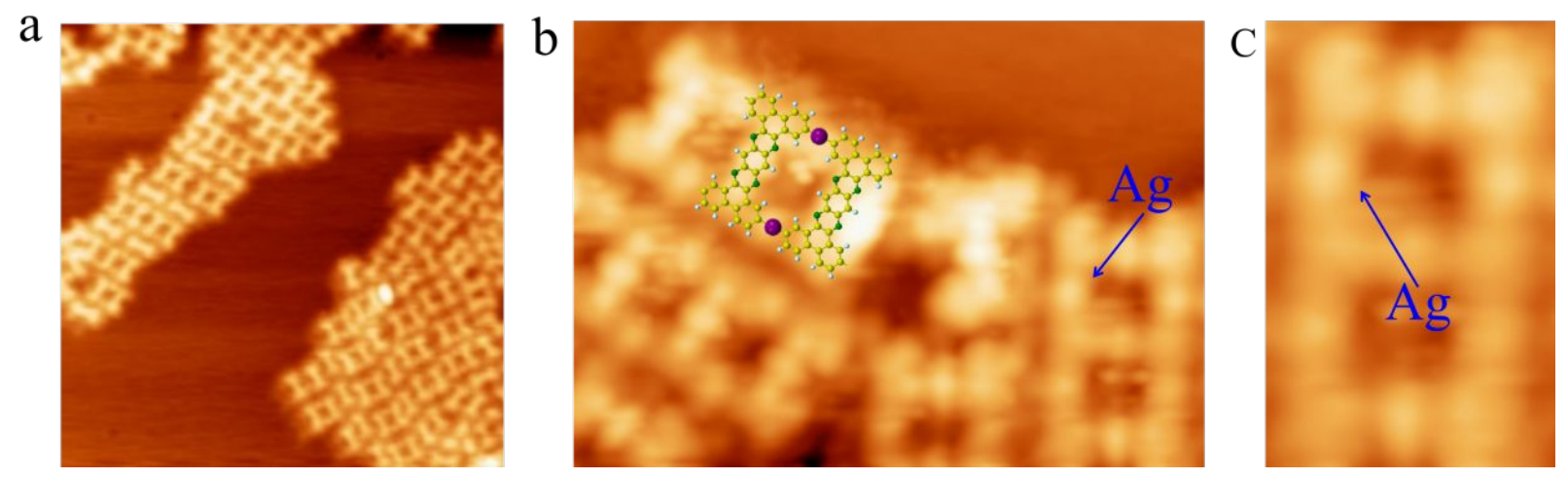

Figure S8. a) STM image indicates the coexistence of 1D and 2D 4N-doping metal-organic frameworks upon depositing TBQP precursor on $\mathrm{Ag}(111)$ and annealing at $100^{\circ} \mathrm{C}$, set point: $V$ $=2.0 \mathrm{~V}$ and $I=27 \mathrm{pA}$, size: $30 \mathrm{~nm} \times 30 \mathrm{~nm}$; b, c) Zoom-in STM image of 1D 4N-doping metalorganic frameworks, a predicted molecular structure is superimposed onto the STM image, set point: $V=0.5 \mathrm{~V}$ and $I=50 \mathrm{pA}$, size: b) $6 \mathrm{~nm} \times 8.5 \mathrm{~nm}$, c) $3.5 \mathrm{~nm} \times 2.4 \mathrm{~nm}$, the Ag atom is highlighted by a blue arrow. 

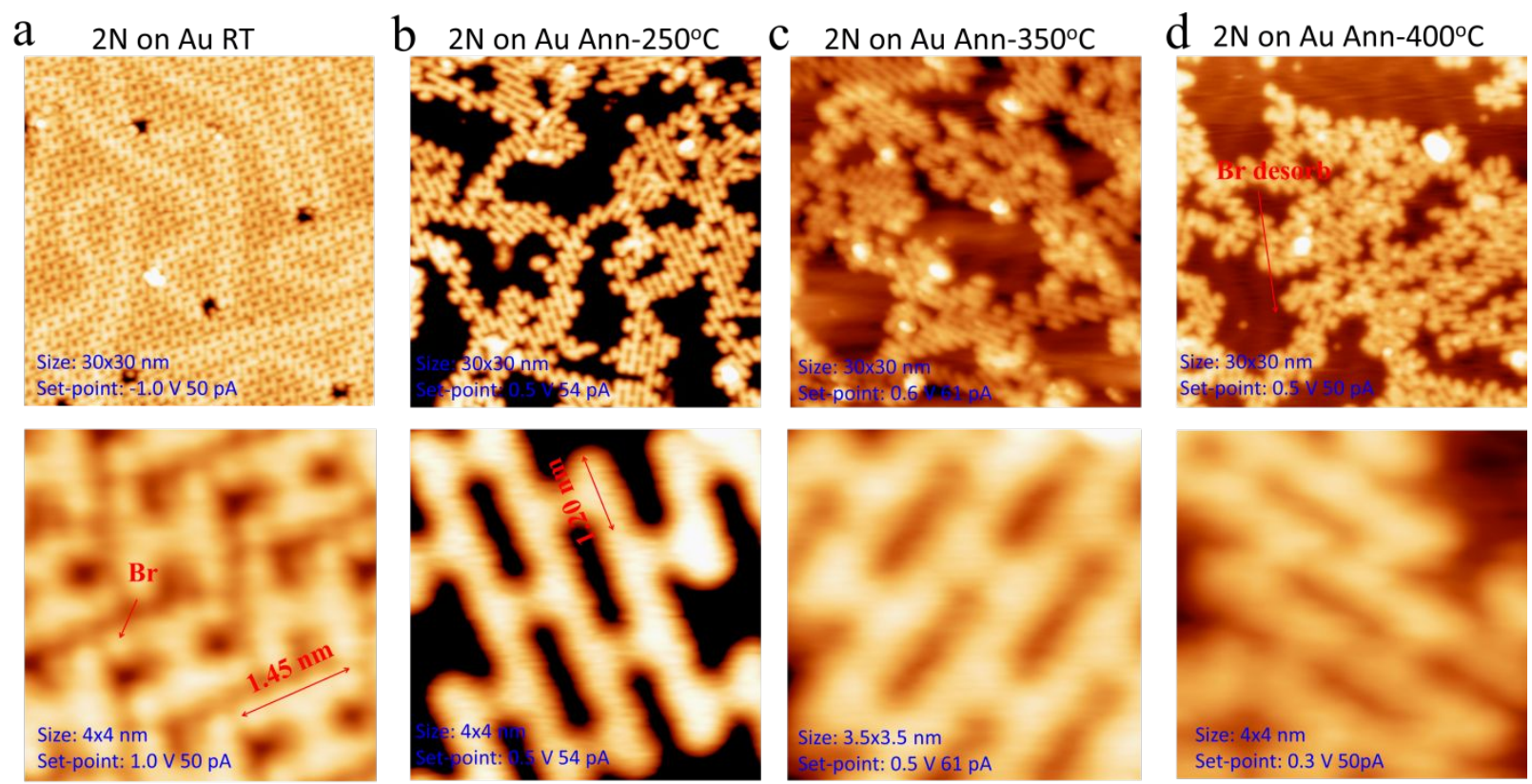

Figure S9. STM images show that the network structure remains intact after annealing to $400{ }^{\circ} \mathrm{C}$.

The step-by-step evolution of the observed structures as a function of the annealing temperature on $\mathrm{Au}(111)$. Large-scale (up) and zoom-in (down) STM images show the observed structure of 2N-doped molecule on Au substrate at different annealing temperatures. 
a $4 \mathrm{~N}$ on Au Ann- $100^{\circ} \mathrm{C}$
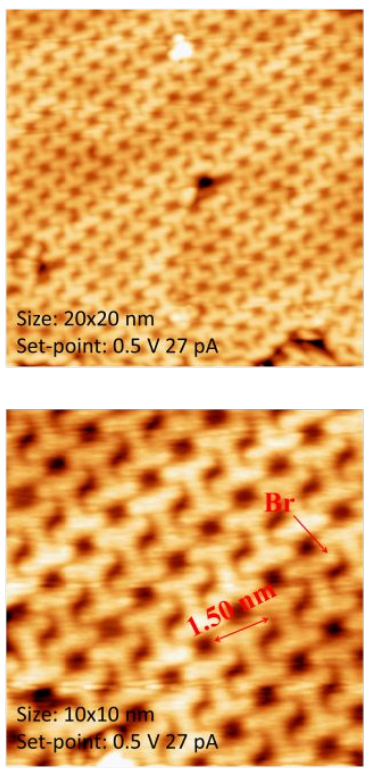

b $4 \mathrm{~N}$ on Au Ann $-150^{\circ} \mathrm{C}$
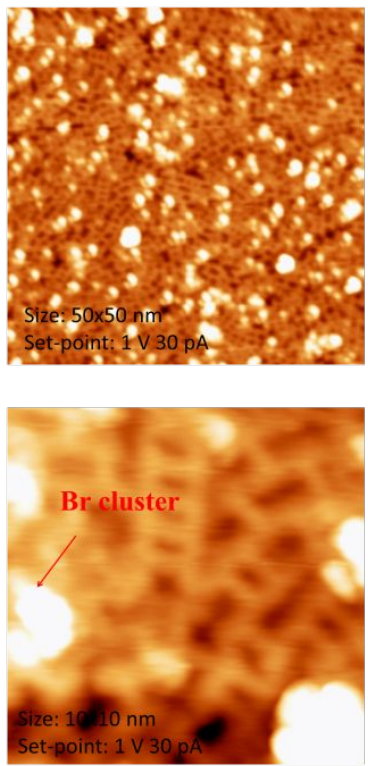

C $4 \mathrm{~N}$ on Au Ann- $200^{\circ} \mathrm{C}$
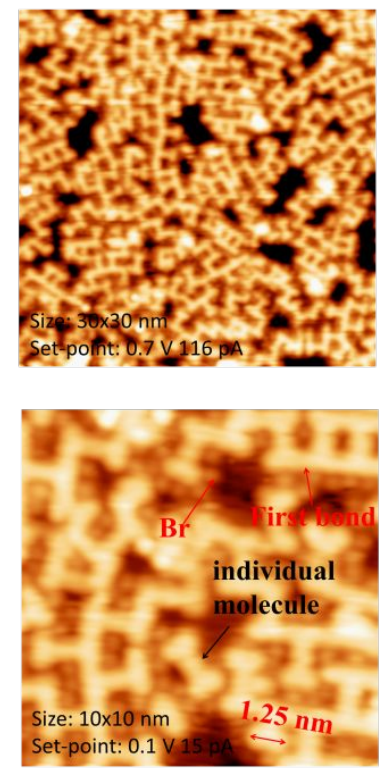

d $4 \mathrm{~N}$ on Au Ann- $250^{\circ} \mathrm{C}$
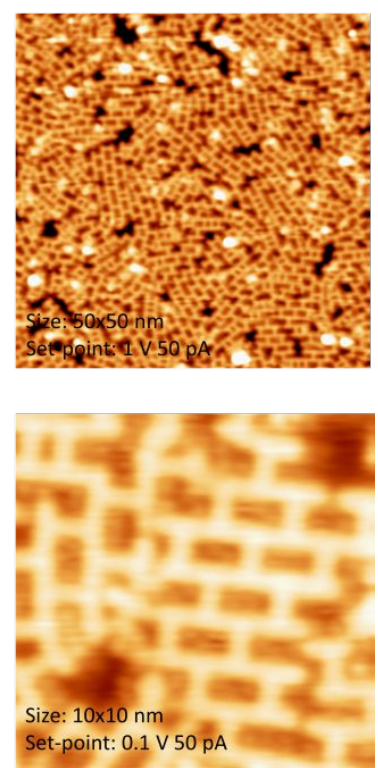

Figure S10. The step-by-step evolution of the observed structures as a function of the annealing temperature on $\mathrm{Au}(111)$. Large-scale (up) and zoom-in (down) STM images show the observed structure of $1 \mathrm{ML} 4 \mathrm{~N}$-doped molecule on Au substrate at different annealing temperatures.

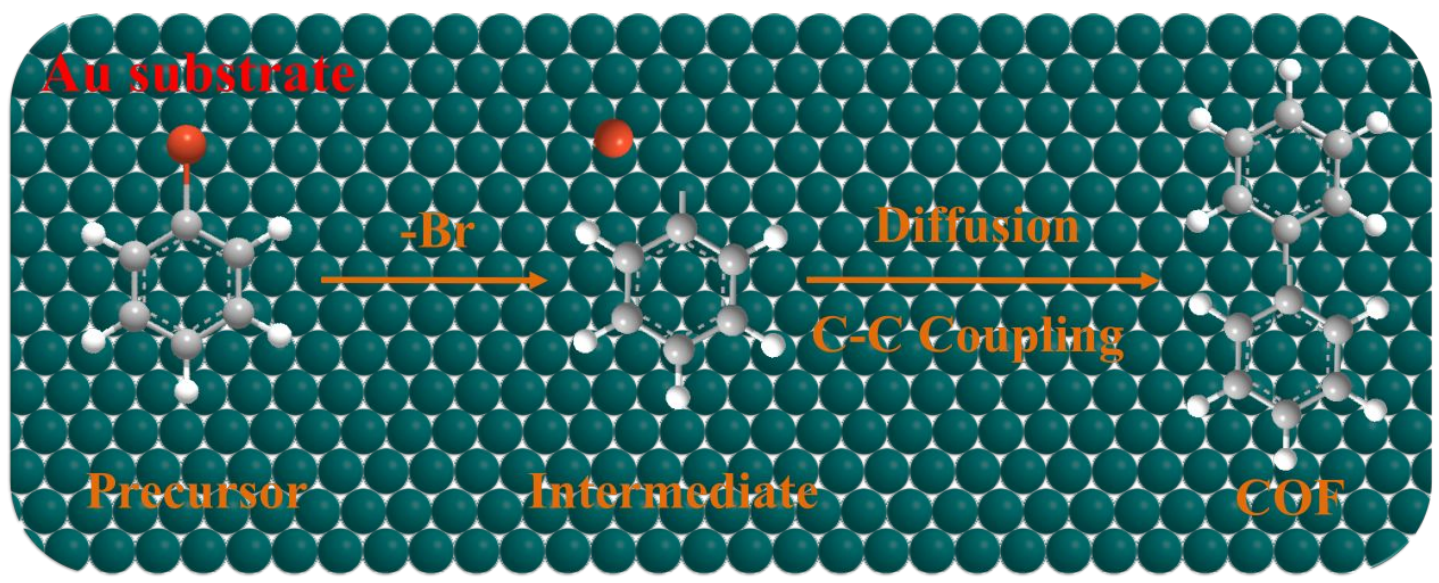

Figure S11. A proposed Ullmann reaction path for $4 \mathrm{~N}$ and $2 \mathrm{~N}$ atoms doping molecules on Au(111). Red (bromine), grey (carbon), white (hydrogen), and dark green (gold). 
a $\quad 4 \mathrm{~N}$ on $\mathrm{Ag} 25^{\circ} \mathrm{C}$
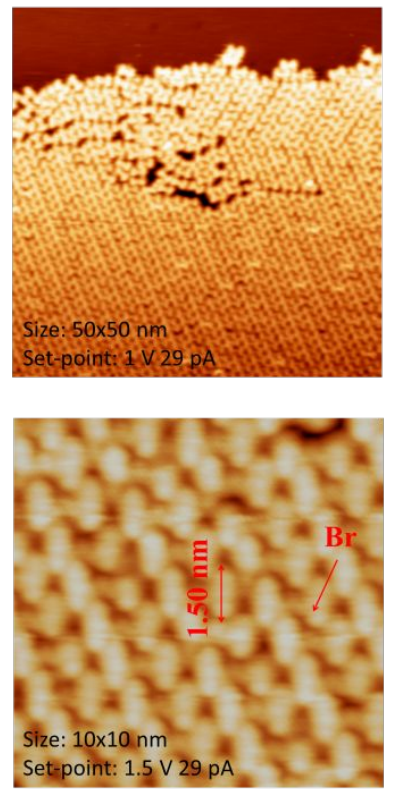

b $4 \mathrm{~N}$ on $\mathrm{Ag}$ Ann $-100^{\circ} \mathrm{C}$
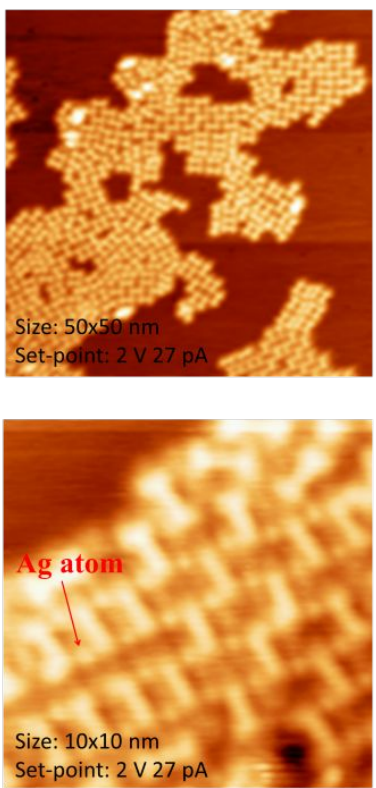

C $4 \mathrm{~N}$ on $\mathrm{Ag}$ Ann $-150^{\circ} \mathrm{C}$
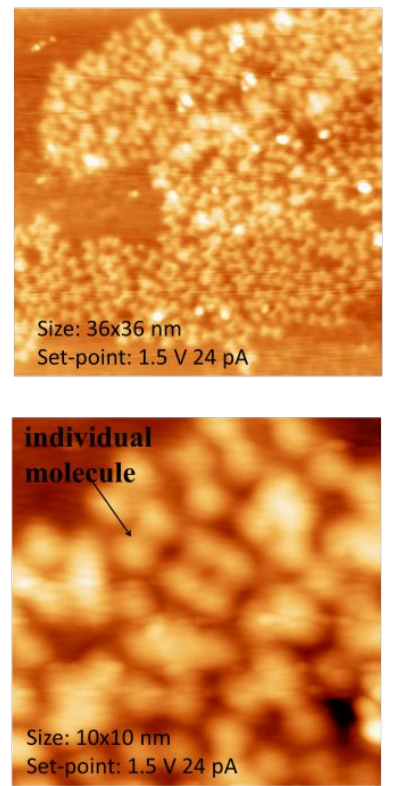

$4 \mathrm{~N}$ on $\mathrm{Ag}$ Ann- $250^{\circ} \mathrm{C}$
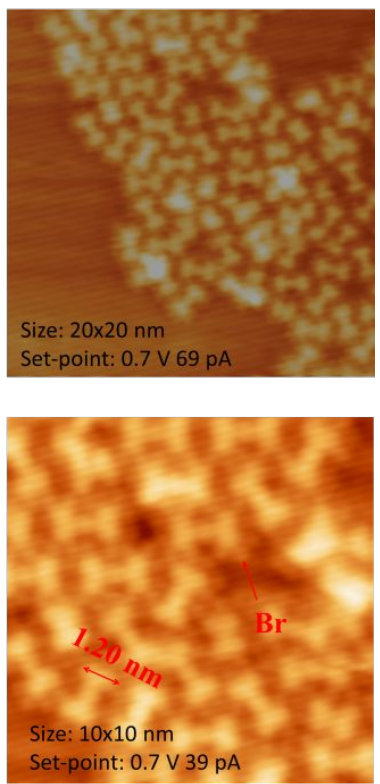

Figure S12. The step-by-step evolution of the observed structures of $4 \mathrm{~N}$ atoms doping molecule on $\operatorname{Ag}(111)$. Large-scale (up) and zoom-in (down) STM images show the observed structure of $4 \mathrm{~N}$ atoms doping molecule on $\mathrm{Ag}$ substrate at different annealing temperatures. 

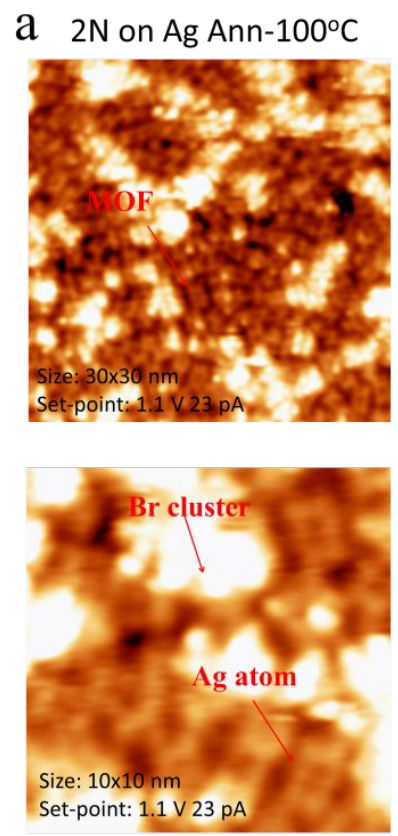

b $2 \mathrm{~N}$ on $\mathrm{Ag} \mathrm{Ann}-150^{\circ} \mathrm{C}$
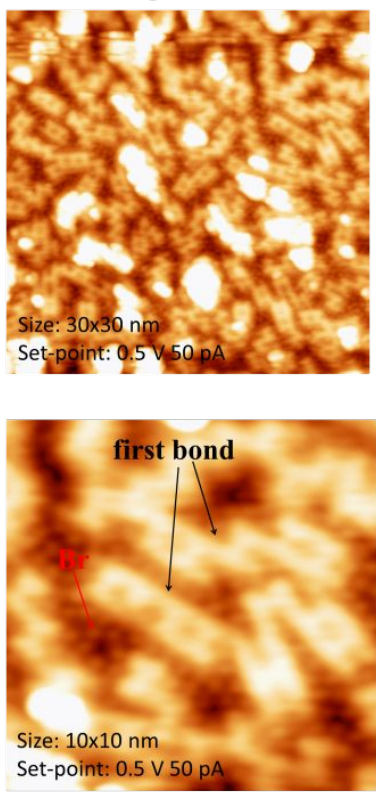
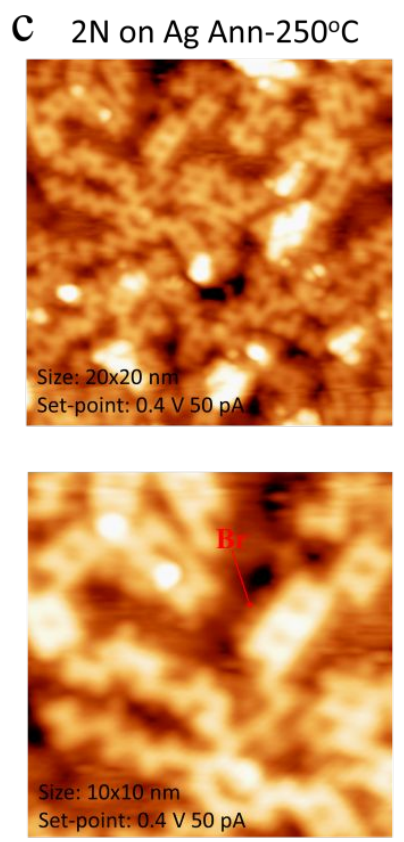
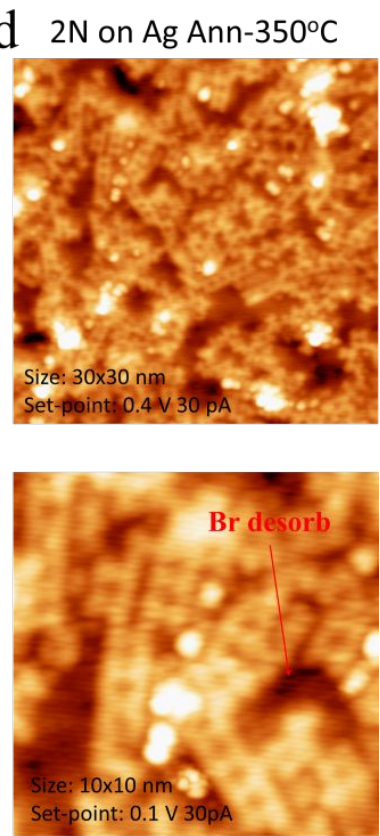

Figure S13. The step-by-step evolution of the observed structures of $2 \mathrm{~N}$ atoms doping molecule on $\operatorname{Ag}(111)$. Large-scale (up) and zoom-in (down) STM images show the observed structure of $2 \mathrm{~N}$ atoms doping molecule on $\mathrm{Ag}$ substrate at different annealing temperatures.

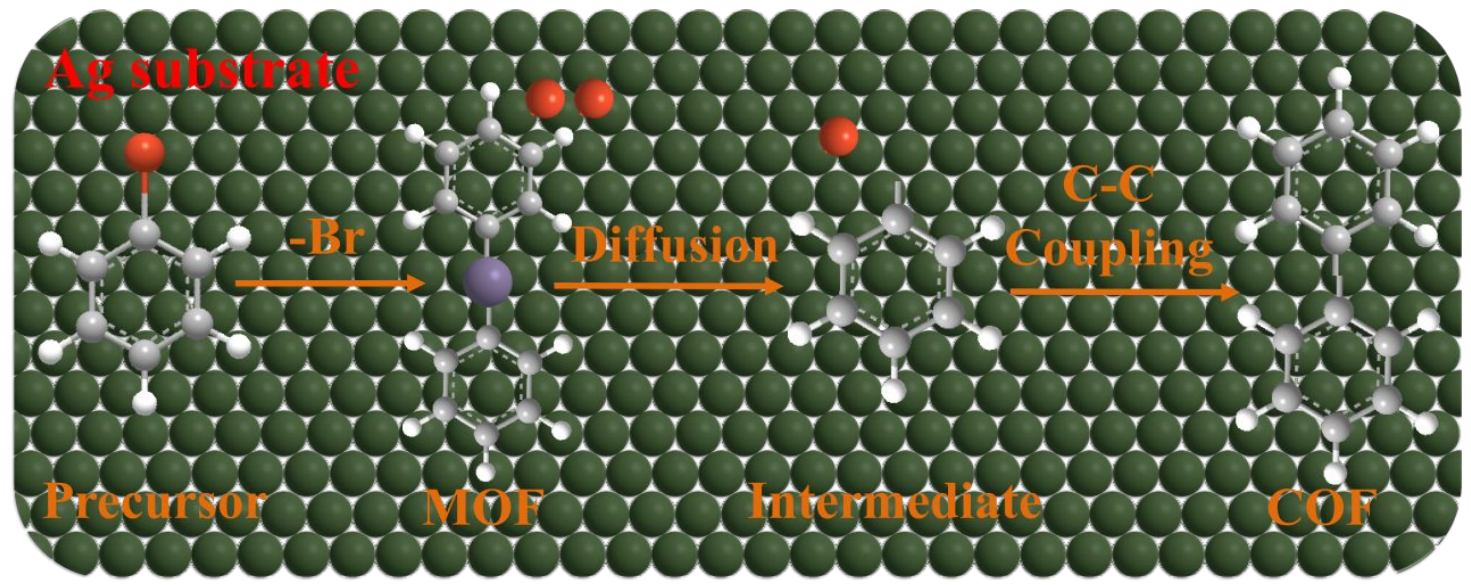

Figure S14. A proposed Ullmann reaction path for $4 \mathrm{~N}$ and $2 \mathrm{~N}$ atoms doping molecules on $\operatorname{Ag}(111)$. Red (bromine), grey (carbon), white (hydrogen), and dark green (silver). 

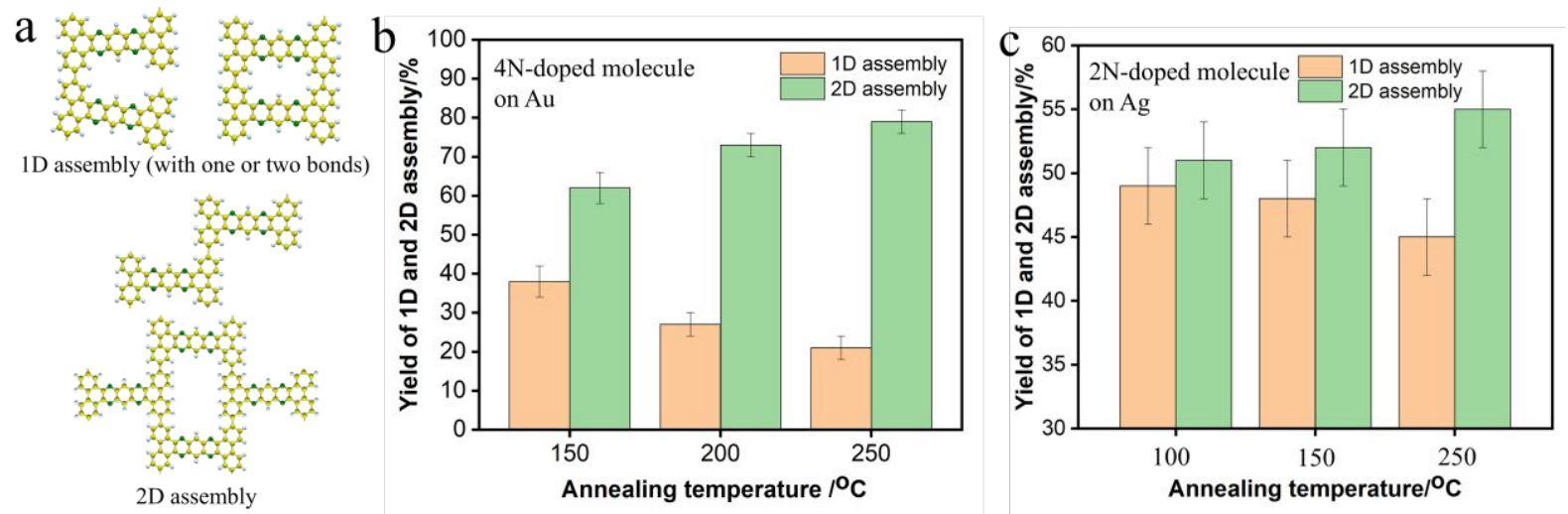

Figure S15. a) 1D- and 2D- assembly configurations; b) Statistical yield of $1 \mathrm{D}$ and 2D molecular assembly of $4 \mathrm{~N}$-doped molecule on $\mathrm{Au}(111)$ obtained after annealing at $150{ }^{\circ} \mathrm{C}, 200$ ${ }^{\circ} \mathrm{C}, 250{ }^{\circ} \mathrm{C}$, respectively; c) Statistical yield of $1 \mathrm{D}$ and $2 \mathrm{D}$ molecular assembly of $2 \mathrm{~N}$-doped molecule on $\operatorname{Ag}(111)$ obtained after annealing at $100{ }^{\circ} \mathrm{C}, 150{ }^{\circ} \mathrm{C}, 250{ }^{\circ} \mathrm{C}$, respectively. 
Table 1. Summary of carbon nitride monolayer with tunable pore size, 1D-2N-COF presents one dimensional two nitrogen atoms doping covalent organic framework and 2D-4N-MOF presents two dimensional four nitrogen atoms doping metal-organic frameworks, others are named similarly, both theoretical pore size and measured pore size (with error bar) were displayed.

\begin{tabular}{c|c|c|c|ccc} 
Pore size & $1 \mathrm{D}-2 \mathrm{~N}-\mathrm{COF}$ & 2D-2N-COF & 1D-4N-COF & 2D-4N-COF & 1D-4N-MOF & 2D-4N-MOF \\
\hline Theory/nm & $0.31 \times 0.57$ & $0.31 \times 1.42$ & $0.38 \times 0.79$ & $0.79 \times 1.24$ & $0.68 \times 0.79$ & $0.79 \times 1.85$ \\
\hline Measure $/ \mathbf{n m}$ & $0.31 \pm 0.05$ & $0.30 \pm 0.05$ & $0.42 \pm 0.06$ & $0.79 \pm 0.05$ & $0.67 \pm 0.06$ & $0.79 \pm 0.06$ \\
& $\mathrm{x} 0.56 \pm 0.05$ & $\mathrm{x} 1.40 \pm 0.06$ & $\mathrm{x} 0.78 \pm 0.05$ & $\mathrm{x} 1.25 \pm 0.05$ & $\mathrm{x} 0.79 \pm 0.06$ & $\mathrm{x} 1.86 \pm 0.05$
\end{tabular}

